\title{
Clinical significance and role of LKB1 in gastric cancer
}

\author{
SHANSHAN JIANG ${ }^{1}$, RENSHENG CHEN ${ }^{2}$, JIANAN YU ${ }^{3}$, NIANSHUANG LI ${ }^{1}$, RONG KE $^{1}$, LINGYU LUO $^{1}$, \\ JUNRONG ZOU ${ }^{1}$, JIANGNAN ZHANG ${ }^{4}$, KUNHE ZHANG $^{1}$, NONGHUA LU ${ }^{1}$ and DEQIANG HUANG ${ }^{1}$ \\ ${ }^{1}$ Research Institute of Digestive Diseases and ${ }^{2}$ Department of Pathology, The First Affiliated Hospital of Nanchang University, \\ Nanchang, Jiangxi 330006; ${ }^{3}$ Department of General Surgery, Beijing Friendship Hospital, Capital Medical University, \\ Beijing 100050; ${ }^{4}$ Department of General Surgery, The First Affiliated Hospital of Nanchang University, \\ Nanchang, Jiangxi 330006, P.R. China
}

Received November 19, 2014; Accepted August 7, 2015

DOI: $10.3892 / \mathrm{mmr} .2015 .4508$

\begin{abstract}
Liver kinase B1 ( $L K B 1)$ functions as a tumor suppressor gene, and loss in the expression of LKB1 contributes to human carcinogenesis and tumor progression. The present study investigated the association between $L K B I$ and gastric cancer. SGC-7901 gastric cancer cell lines and 63 patients with gastric cancer were examined in the present study, and lentivirus transfection, reverse transription-quantitative polymerase chain reaction and flow cytometric analyses were performed. By examining the expression of LKB1 using immunohistochemical analyses, the present study found that the expression of LKB1 was reduced in the gastric cancer tissues, and restoration of the expression of LKB1 reduced tumor cell viability, migration rate and the expression of CD44, induced cell cycle arrest at the G2 phase of the cell cycle, and increased the sensitivity of the gastric cancer cells to anticancer drugs. LKB1 protein is a tumor-suppressor in gastric cancer and may be potentially be developed as a novel gene therapy target in the treatment of gastric cancer.
\end{abstract}

\section{Introduction}

Gastric cancer is a significant worldwide health problem, which has high rates of morbidity and mortality and is the fifth most common type of cancer and the third leading cause of annual cancer-associated mortality worldwide (1). In China, gastric cancer morbidity and mortality rates are double the global mean (2). Helicobacter pylori is the most significant risk factor for gastric cancer, contributing to between 60 and $70 \%$ of gastric cancer cases globally (3). Other risk factors include chronic gastritis, consumption of smoked or salted fish

Correspondence to: Dr Deqiang Huang, Research Institute of Digestive Diseases, The First Affiliated Hospital of Nanchang University, 17 Yongwaizen Street, Nanchang, Jiangxi 330006, P.R. China

E-mail: hdq0515@163.com

Key words: gastric cancer, liver kinase B1, immunohistochemistry, cell viability, cell cycle distribution, migration and other meat, consumption of pickled vegetables, obesity, tobacco use, type A blood and geographic location, including China, Japan, Southern and Eastern Europe and South and Central America $(3,4)$. The incidence and mortality rates of gastric cancer are decreasing due to the eradication of $H$. pylori and advances in early endoscopic detection; however, the treatment of gastric cancer remains a challenge, as surgery is the only effective cure available to patients (3). Gastric cancer is not particularly sensitive to chemotherapy and non-surgical interventions are usually only used palliatively to reduce tumor size or relieve symptoms of the disease (5). Thus, it is important to improve current understanding of the molecular mechanisms of gastric carcinogenesis, to enable the identification and development of novel strategies for the prevention and treatment of gastric cancer.

A substantial number of studies have demonstrated that the development of gastric cancer, as with the majority of types of human cancer, involves gene alterations, including p53 or mTOR, or the process of epithelial-mesenchymal transition $(6,7)$. The present study aimed to focus on the role of serine/threonine kinase 11 (STK11), also termed liver kinase $\mathrm{B} 1(L K B 1)$, in gastric cancer.

LKB1 is ubiquitously expressed in human cells and is a necessary element in cell metabolism, which is required to maintain energy homeostasis. LKB1 can regulate cell polarity and can function as a tumor suppressor by inhibiting the growth and migration of cells, inducing cell cycle arrest, and promoting tumor cell apoptosis (8-11). The majority of these effects are mediated through the activation of adenine monophosphate-activated protein kinase (AMPK) and AMPK-associated kinases $(12,13)$. At the molecular level, LKB1 can also inhibit the mammalian target of rapamycin (mTOR) signaling pathway to regulate cell autophagy following the activation of AMPK (14), and can inhibit tumor cell glycolysis and lipid synthesis to reduce the rate of tumor cell growth and migration (15-17). A reduction in the expression of LKB1 alters cell polarity and affects cell adhesion, promoting the transformation of normal cells and tumor metastasis (10). LKB1 loss-of-function mutations are an etiological factor in Peutz-Jeghers syndrome, an autosomal dominant genetic disorder $(18,19)$. $L K B 1$ is mutated in a several different sporadic cancer types, including lung adenocarcinoma and breast cancer (20) and restoration of the expression of LKB1 
suppresses lung cancer cell invasion and metastasis (21). In the present study, the expression of LKB1 was examined in human gastric cancer tissue specimens, and the effects of the expression of LKB1 in gastric cancer cells were assessed in vitro to understand the role of LKB1 in gastric cancer. The results of the present study may assist in the future development of novel gene therapies against gastric cancer.

\section{Materials and methods}

Tissue specimens. A total of 63 gastric cancer tissue samples were obtained from 63 patients as unique cases from the Department of Pathology, The First Hospital of Nanchang University (Nanchang, China). The patients underwent gastrostomy in the Surgery Department at the First Hospital of Nanchang University between March 2010 and April 2012, and all patients were diagnosed histologically with gastric adenocarcinoma (Table I). The present study was approved by the ethical committee of The First Affiliated Hospital of Nanchang University (Nanchang, China). The tissue specimens were collected by surgical resection and deposited to the pathological specimen library of The First Affiliated Hospital of Nanchang University.

Immunohistochemistry. Immunohistochemistry was performed using a ZSGB-bio kit (ZSGB-BIO, Beijing, China) according to the manufacturer's instructions. Briefly, citrate buffer (cat. no. ZLI-9064; ZSGB-BIO) was used for antigen retrieval, and the tissue sections $(2 \times 1 \mathrm{~cm}$ and $2 \times 3 \mathrm{~cm})$ were incubated at $4^{\circ} \mathrm{C}$ with monoclonal goat anti-human LKB1 antibody at a dilution of 1:250 (cat. no. sc-32245; Santa Cruz Biotechnology, Inc., Santa Cruz, CA, USA) overnight. The secondary antibody was rabbit anti-mouse IgG (cat. no. PV9000; ZSGB-BIO), which was incubated with the tissue sections for $4 \mathrm{~h}$ at $37^{\circ} \mathrm{C}$. The reaction was developed using 3,3'-diaminobenzidine (DAB; ZSGB-BIO) and counterstained with hematoxylin (Yulu Experimental Equipment Co., Ltd., Nanchang, China). The immunostained tissue sections were evaluated semi-quantitatively under a light-microscope (Eclipse Ni; Nikon Corporation, Tokyo, Japan), according to the immunoreactive score (IRS), which evaluates the staining intensity and the percentage of positive staining (22).

Cell culture and treatment. HEK-293T cells were obtained from the Research Institute of Digestive Diseases (Nanchang, China). The SGC-7901 cell line was obtained from the Research Institute of Digestive Diseases and cultured in high glucose Dulbecco's modified Eagle's medium (DMEM) containing $10 \%$ fetal bovine serum (FBS) and $100 \mathrm{U} / \mathrm{ml}$ penicillin $/ 100 \mathrm{~g} / \mathrm{ml}$ streptomycin solution (all GE Healthcare Life Sciences, Logan, UT, USA) at $37^{\circ} \mathrm{C}$ with $5 \% \mathrm{CO}_{2}$. For anticancer drug treatment, SGC-7901 cells and stably expressing LKB1 cells were seeded into 96-well plates at a density of $3 \times 10^{3}$ cells/well, and treated with various concentrations of anticancer drugs for 2 days in a cell incubator at $37^{\circ} \mathrm{C}$. The anti-cancer drugs and the concentrations used were as follows: 10, 20, 40 and $80 \mu \mathrm{M}$ 5-fluorouracil (5-FU; Sigma-Aldrich, St. Louis, MO, USA) 25, 50 and $100 \mu \mathrm{M}$ oxaliplatin (Sanofi S.A., Paris, France) and 5, 10, 20 and $40 \mu \mathrm{M}$ irinotecan (Pfizer, Inc. New York, NY, USA).
Table I. Correlation between the expression of LKB1 and clinicopathological parameters in patients with gastric cancer.

\begin{tabular}{llllr}
\hline & \multicolumn{4}{c}{ Expression of LKB1 } \\
\cline { 2 - 5 } Parameter & $\mathrm{n}$ & Negative & Positive & P-value \\
\hline Gender & & & & 0.42 \\
Male & 48 & 41 & 7 & 0.75 \\
Female & 15 & 14 & 1 & \\
Borrmann & & & & 0.75 \\
I and II & 36 & 31 & 5 & \\
III and IV & 27 & 24 & 3 & \\
TNM & & & 3 & \\
I and II & 27 & 24 & 5 & \\
III and IV & 36 & 31 & & \\
\hline
\end{tabular}

LKB1, liver kinase B1; TNM, tumor-node-metastasis.

$m R N A$ isolation and reverse transcription-quantitative polymerase chain reaction ( $R T-q P C R)$. Total cellular $\mathrm{mRNA}$ was isolated using a Labserv Universal RNA kit (KFR0-803096 IX96) from Thermo Fisher Scientific (Waltham, MA, USA), according to the manufacturer's instructions, and then reverse transcribed into cDNA using a QuantScript RT kit (TianGen Biotech, Beijing, China). qPCR was performed using a GoTaq ${ }^{\circledR}$ qPCR Master mix kit from Promega Corporation (Madison, WI, USA), according to the manufacturer's instructions. A total of $2 \mu \mathrm{l} \mathrm{cDNA,} \mathrm{2X} 10 \mu \mathrm{l} \mathrm{GoTaq}^{\circledR}$ qPCR Master Mix, 100X $0.2 \mu \mathrm{l}$ CXR Reference Dye, $0.4 \mu \mathrm{l}$ forward primer, $0.4 \mu \mathrm{l}$ reverse primer, and $7 \mu 1$ nuclease-free water were used for the reaction. The LKB1 primers [Generay Biotech (Shanghai) Co., Ltd., Shanghai, China] were forward 5'-CGCTCTCTGACC TGCTGAAA-3' and reverse 5'-CACCGTGAAGTCCTGAGT GT-3', which produced a 260 bp PCR product. The internal control GAPDH primers were forward 5'-CAGGGCTGCTTT TAACTCTGGT-3' and reverse 5'-GATTTTGGAGGGATC TCGCT-3', which produced a 199 bp PCR product. The qPCR amplification was at $95^{\circ} \mathrm{C}$ for $2 \mathrm{~min}$, followed by 40 cycles of $95^{\circ} \mathrm{C}$ for $15 \mathrm{sec}$ and $58^{\circ} \mathrm{C}$ for $30 \mathrm{sec}$. The mRNA expression levels of LKB1 were quantified and compared with GAPDH mRNA using the $2^{-\triangle \Delta C T}$ method (23).

Protein extraction and western blot analysis. Total cellular protein was extracted using protein lysis buffer, as previously described (24). The protein concentration was then measured using the Bradford method (25). Subsequently, the protein samples were separated by $10 \%$ sodium dodecylsulphate-polyacrylamide gel (Beijing Solarbio Science \& Technology Co., Ltd., Beijing, China) electrophoresis at $60 \mathrm{~V}$ for $3-4 \mathrm{~h}$. The proteins were then transferred onto a nitrocellulose membrane (Whatman International Ltd., Maidstone, UK) by wet electroblotting with a constant current of $200 \mathrm{~mA}$ for $2 \mathrm{~h}$ at room temperature. The membrane was subsequently blocked for $1 \mathrm{~h}$ in 5\% skim milk-Tris-buffered saline (TBS; Beijing Solarbio Science \& Technology Co., Ltd.). The membrane was then incubated with primary antibody at $4^{\circ} \mathrm{C}$ overnight. $\beta$-actin 


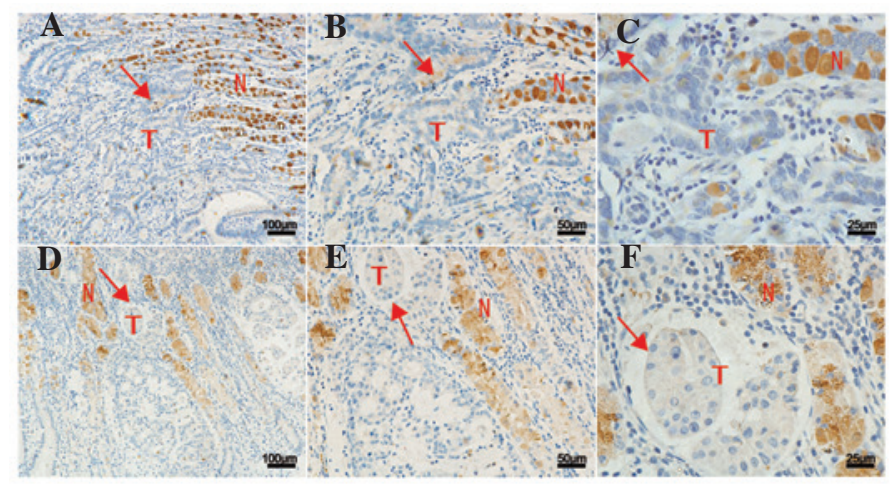

G

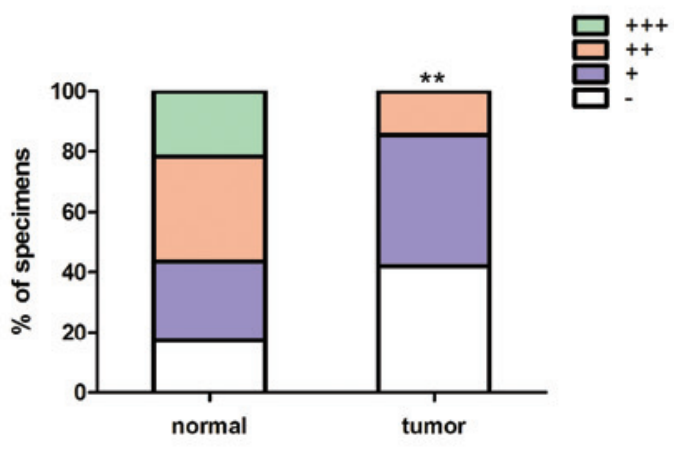

Figure 1. Immunohistochemical staining of LKB1 protein in gastric cancer tissue specimens. (A-C) Tissue specimens from the one patient; (D-F) tissue specimens from a different patient. Red arrows indicate the location of the tumor. (G) Percentage of specimens expressing low or high levels of LKB1 in gastric cancer tissue specimens. -, indicates a staining index score $<2$; + , a staining index score is $>3$ and $<5$; ++ , a staining index score $>6$ and $<8$; and +++ , a staining index score $>9$ and $<12$. ${ }^{* *} \mathrm{P}<0.01$, vs. adjacent normal tissues. $\mathrm{T}$, tumor tissue; $\mathrm{N}$, adjacent normal tissue.

antibody (ZSGB-BIO) was used as an internal control. The following day, the membrane was washed with Tween 20 three times (15 min each), followed by incubation with horseradish peroxidase-labeled goat anti-mouse $\mathrm{IgG}$ (ZSGB-BIO) at $4^{\circ} \mathrm{C}$ for $4 \mathrm{~h}$. Following incubation, the blot was developed using a SuperSignal West Pico Chemiluminescence kit (Thermo Fisher Scientific) and detected and quantified using a ChemiDoc XRS+ system (Bio-Rad Laboratories, Inc., Hercules, CA, USA).

Packaging of the lentivirus and cell infection. A lentivirus vector carrying LKB1 cDNA was obtained from the Dr Zhijun Luo of the School of Medicine, Boston University (Boston, NY, USA). To package the lentivirus, HEK-293T cells were passaged in $10 \mathrm{~cm}$ culture dishes $\left(1 \times 10^{6}\right.$ cells $)$ and transfected with either the LKB1 vector or control vector (10 $\mathrm{ng}$ of each target plasmid and a packaging plasmid) using a calcium phosphate transfection method. Briefly, all the plasmids were mixed with $62 \mu 12 \mathrm{M} \mathrm{CaCl}_{2}$ (Beijing Solarbio Science \& Technology Co., Ltd.) and $\mathrm{ddH}_{2} \mathrm{O}$, forming a total volume of $500 \mu \mathrm{l}$, and the solution was subsequently added into $2 \mathrm{X}$ Hanks' Balanced Salts (Beijing Solarbio Science \& Technology Co., Ltd.), incubated at room temperature for $20 \mathrm{~min}$, and finally incubated with the cells for $12 \mathrm{~h}$. When the cells reached 70 to $80 \%$ confluency, the cell culture supernatant containing the lentivirus was collected using a PEG-8000 method to concentrate and purify the virus particles. Briefly, the virus supernatant was filtered with a $0.45 \mu \mathrm{m}$ microfiltration membrane, then added to $5 \mathrm{X}$ PEG-8000 $\mathrm{NaCl}$ solution (Beijing Solarbio Science \& Technology Co., Ltd.), and then used to treat the cells prior to incubation at $4^{\circ} \mathrm{C}$ overnight. After $24 \mathrm{~h}$, the solution was centrifuged at $4,000 \mathrm{x}$ g for $20 \mathrm{~min}$ at $4^{\circ} \mathrm{C}$, and the supernatant was discarded. Multiplicity of infection (MOI) was assessed by diluting the concentrated lentivirus in a series of gradients, which were then used to infect the 293T cells. Following incubation for $48 \mathrm{~h}$ in a cell incubator, the medium of the cells was changed, and after 4 days, RNA was extracted from the cells to assess the MOI by comparing the $\mathrm{Ct}$ values of the control compared with the experimental group.

To infect the gastric cancer cells with the lentivirus, $1 \times 10^{5}$ SGC-7901 cells were grown in $6 \mathrm{~cm}$ culture dishes and infected with $200 \mu \mathrm{l}$ viral supernatant using polybrene
(GeneChem Co., Ltd., Shanghai, China) for $12 \mathrm{~h}$ at $37^{\circ} \mathrm{C}$, following which the growth medium was replaced with medium containing $1 \mu \mathrm{g} / \mathrm{ml}$ puromycin (Beijing Solarbio Science \& Technology Co., Ltd.) to screen for stable cells (stable cells remain live following puromycin treatment).

Cell viability MTT assay. The cells were inoculated into three 96-well plates at a density of $3 \times 10^{3}$ cells per well and grown for up to $72 \mathrm{~h}$. At the end of each experiment, $20 \mu \mathrm{l} \mathrm{MTT}$ (5 $\mu \mathrm{g} / \mu 1$; Beijing Solarbio Science \& Technology Co., Ltd.) was added to the cell culture medium and the cells were incubated at $37^{\circ} \mathrm{C}$ for another $4 \mathrm{~h}$. The medium was then aspirated and $150 \mu \mathrm{l}$ dimethyl sulfoxide (DMSO) was added to each well. Subsequently, the optical density value was measured at a wavelength of $490 \mathrm{~nm}$ using a SpectraMax M Series Multi-Mode microplate reader (Molecular Devices, Sunnyvale, CA, USA). The experiments were performed in nine replicates and repeated at least three times.

Tumor cell wound-healing assay. The stable cells were trypsinized (Gibco-BRL,Grand Island, NY, USA) and plated into a six-well plate at a density of $5 \times 10^{6}$ cells per well. Following overnight incubation at $37^{\circ} \mathrm{C}$, two parallel wounds, $\sim 400 \mu \mathrm{m}$ wide, were made in the cell layer using a $10 \mu \mathrm{l}$ pipette tip. Following rinsing three times with phosphate buffered saline (PBS), the cells were cultured in $2 \mathrm{ml}$ DMEM without FBS, supplemented with penicillin/streptomycin, for up to $48 \mathrm{~h}$ at $37^{\circ} \mathrm{C}$. Images were captured of each plate at 0,24 and $48 \mathrm{~h}$ under an inverted microscope (magnification, x100; Eclipse TS100; Nikon, Tokyo, Japan). The cell migration distance was determined by measuring the width of the wound, divided this value by two, and subtracting this value from the initial width of the wound.

Flow cytometric analysis of the expression of CD44. The stable cells were inoculated into a six-well plate at a density of $1 \times 10^{5}$ cells per well, and trypsinized and resuspended the following day at room temperature. The resuspended solution was transferred into two $1.5 \mathrm{ml}$ conical centrifuge tubes and washed twice with PBS following centrifugation of the cells at $94 \mathrm{x} \mathrm{g}$ at $4^{\circ} \mathrm{C}$ for $5 \mathrm{~min}$. Subsequently, either anti-CD44 antibody (Cell Signaling Technology, Inc., Danvers, Massachusetts, 
A

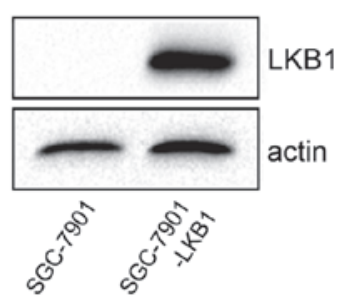

B

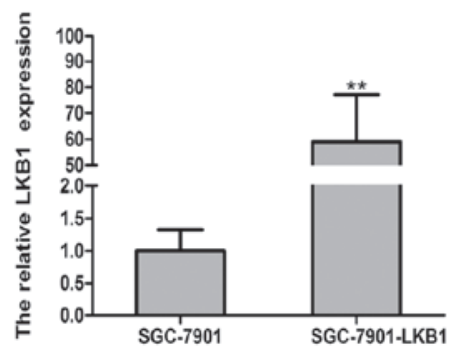

C

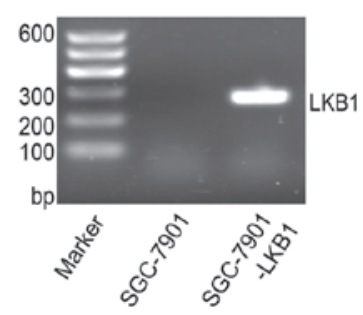

Figure 2. Establishment of a stable LKB1-expressing gastric cancer cell line. (A) Western blot analysis of the protein expression of LKB1 in SGC-7901 and SGC-7901-LKB1 cells. (B) RT-qPCR analysis of the mRNA expression of LKB1 in SGC-7901 and SGC-7901-LKB1 cells. ${ }^{* *}$ P $<0.05$, vs. the SGC-7901 cells. (C) PCR analysis of LKB1 mRNA. Data are presented as the mean \pm standard error of the mean. RT-qPCR, reverse transcription-quantitative polymerase chain reaction; LKB1, liver kinase B1.

A

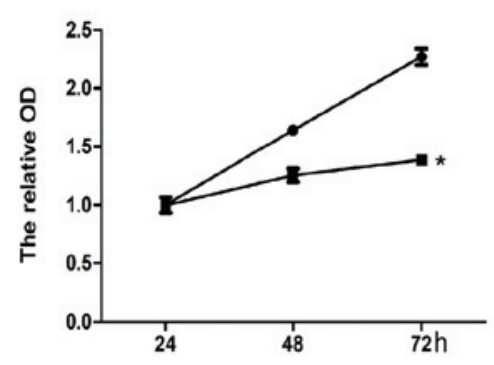

C

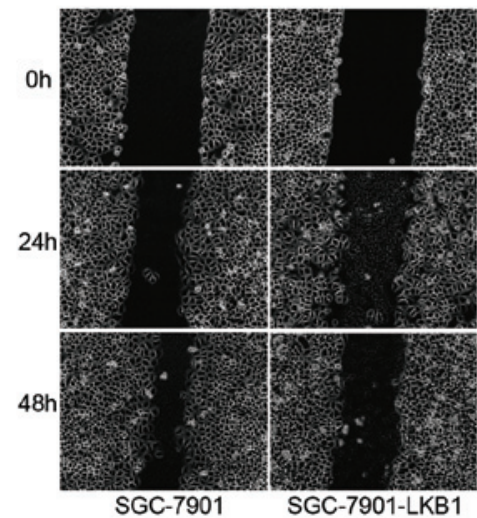

B

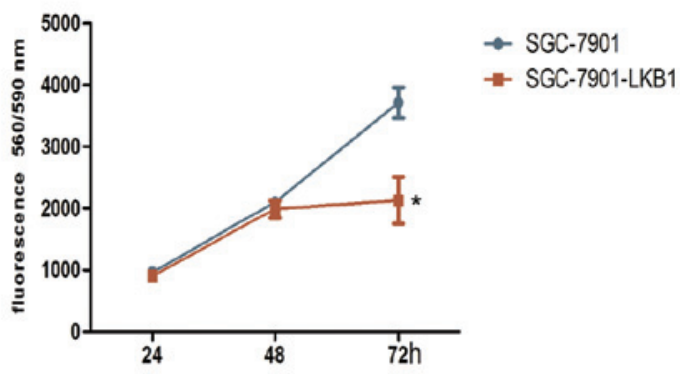

D

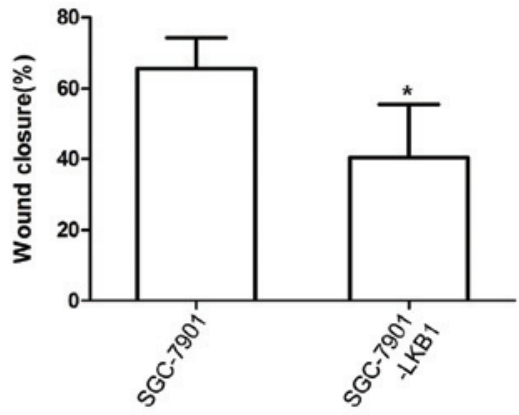

Figure 3. Effects of the expression of LKB1 on the regulation of tumor cell viability and migration in SGC-7901 and SGC-7901-LKB1 cells. (A) MTT assay. (B) Amblue staining for tumor cell viability. (C) Wound-healing assay. The wounds were created at $0 \mathrm{~h}$ and images were captured at 24 and $48 \mathrm{~h}$. The widths of the two cells were compared to determine cell migration. Images are representative of three different time points ( 0,24 and $48 \mathrm{~h}$ ). (D) Quantitative results of the wound-healing assay. "P<0.05, vs. the SGC-7901 cells. Data are presented as the mean \pm standard error of the mean. LKB1, liver kinase B1; OD, optical density.

USA), at a dilution of 1:200, or PBS, as a negative control, were added to the solution and incubated on ice for $30 \mathrm{~min}$ in the dark. The cells were then centrifuged at $845 \mathrm{x}$ g at $4^{\circ} \mathrm{C}$ for $5 \mathrm{~min}$, washed with PBS twice at $94 \mathrm{x}$ g at $4^{\circ} \mathrm{C}$ for $5 \mathrm{~min}$ and suspended in $1 \mathrm{ml}$ PBS for flow cytometric analysis (BD Biosciences, San Jose, CA, USA).

Flow cytometric analysis of cell cycle distribution. The stable cells were inoculated into six-well plates at a density of $1 \times 10^{5}$ cells per well, and trypsinized and resuspended the following day at room temperature. The solution was transferred into two $1.5 \mathrm{ml}$ conical centrifuge tubes and stained using $1 \mathrm{ml}$ propidium iodide (PI; Beijing Solarbio Science \& Technology Co., Ltd.) for $30 \mathrm{~min}$ at $4^{\circ} \mathrm{C}$ in the dark, followed by centrifugation at $845 \mathrm{x} \mathrm{g}$ at $4^{\circ} \mathrm{C}$ for $5 \mathrm{~min}$, washing with
PBS twice at $94 \mathrm{x} \mathrm{g}$ at $4^{\circ} \mathrm{C}$ for $5 \mathrm{~min}$, and resuspending in $1 \mathrm{ml}$ PBS for flow cytometric analysis (BD Accuri ${ }^{\mathrm{TM}}$ C6; BD Biosciences).

Statistical analysis. All data are presented as the mean \pm standard error of the mean and were statistically analyzed using SPSS 17 software (SPSS, Inc., Chicago, IL, USA). An unpaired t-test, one-way analysis of variance was used to determine the statistical significance of data. $\mathrm{P}<0.05$ was considered to indicate a statistically significant difference.

\section{Results}

Expression of LKB1 is lost in gastric cancer tissue. The present study examined the expression of LKB1 in 63 cases 
A

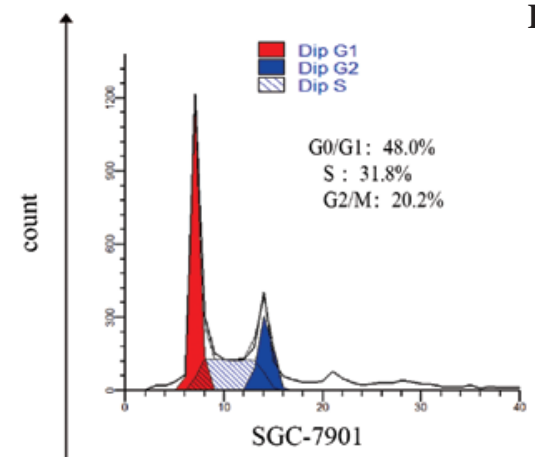

B

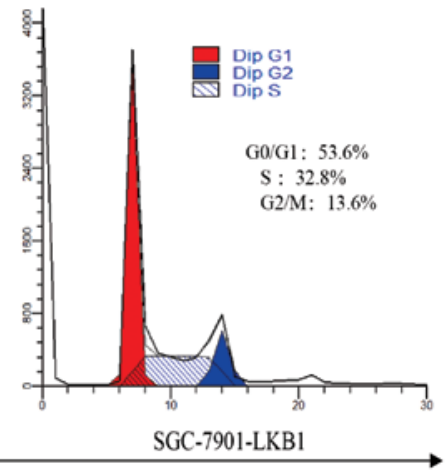

PI

C

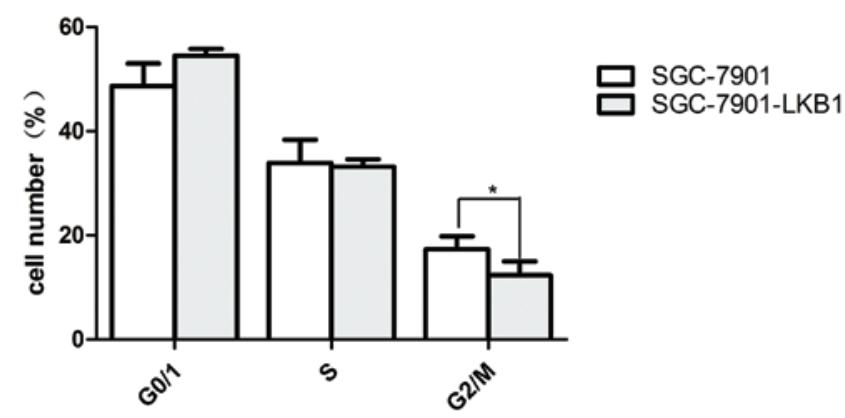

Figure 4. Effects of the expression of LKB1 on the regulation of cell cycle distribution. (A) SGC-7901 cells were analyzed using flow cytometry. (B) SGC-7901-LKB1 cells were analyzed using flow cytometry. ${ }^{*}$ P $<0.05$, vs. the SGC-7901 cells. (C) LKB1-expressing cells exhibited induction of cell cycle arrest in the G2/M phase. Data are presented as the mean \pm standard error of the mean. LKB1, liver kinase B1.

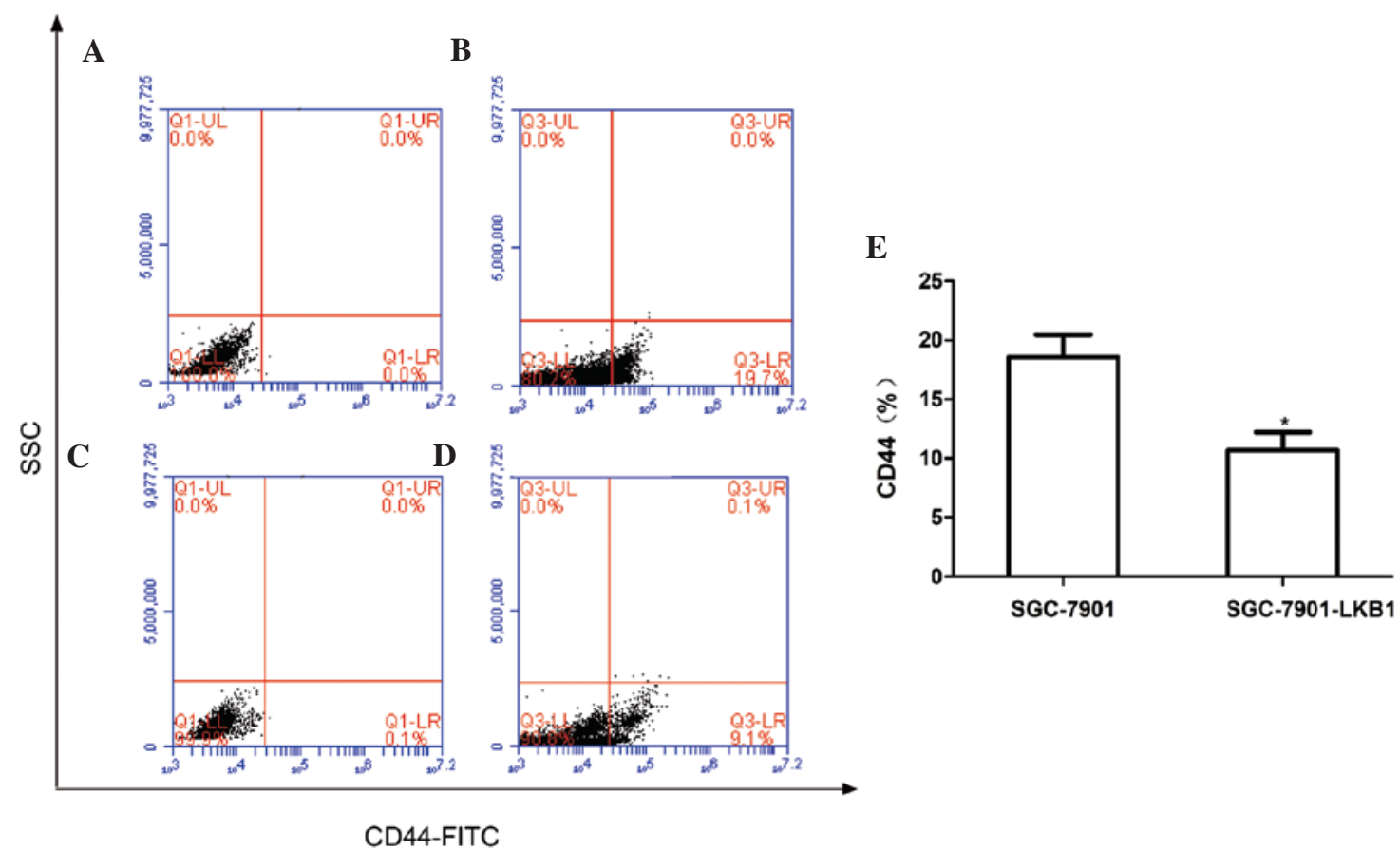

Figure 5. Effects of the expression of LKB1 on the expression of CD44 in gastric cancer cells. (A) SGC-7901 cells were grown and analyzed using flow cytometry. Left quandrant, CD44-negative cells; right quadrant, CD44-positive cells. (B) SGC-7901 cells were grown, CD44-FITC was added and cells were subjected to flow cytometry. (C) SGC-7901-LKB1 cells were grown and analyzed using flow cytometry. (D) SGC-7901-LKB1 cells were grown, CD44-FITC was added and cells were subjected to flow cytometry. (E) Summarized data of the flow cytometry assays. Data are presented as the mean \pm standard error of the mean. "P<0.05, vs. the SGC-7901 cells. LKB1, liver kinase B1; SSC, side scatter; FITC, fluorescein isothiocyanate.

of gastric cancer and found that the expression of LKB1 was significantly lower in the tumor tissue, compared with the adjacent healthy tissues $(\mathrm{P}<0.01$; Fig. 1). Potential associations between the reduction in the expression of LKB1 with the clinicopathological data from the 63 patients were then examined. The expression of LKB1 was not associated 


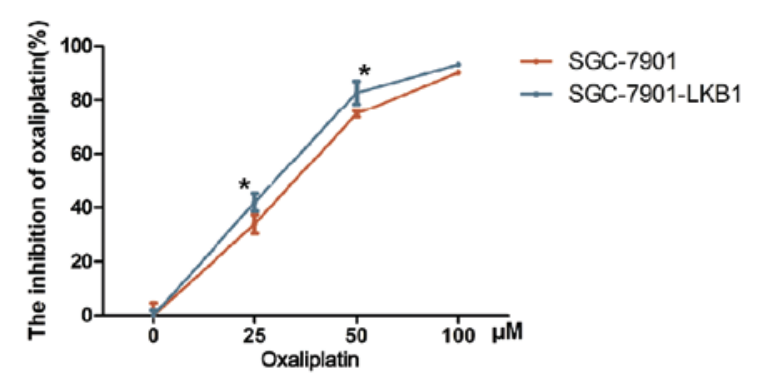

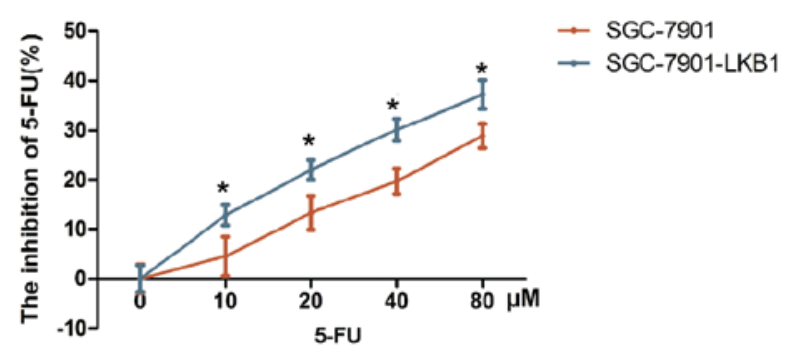

C

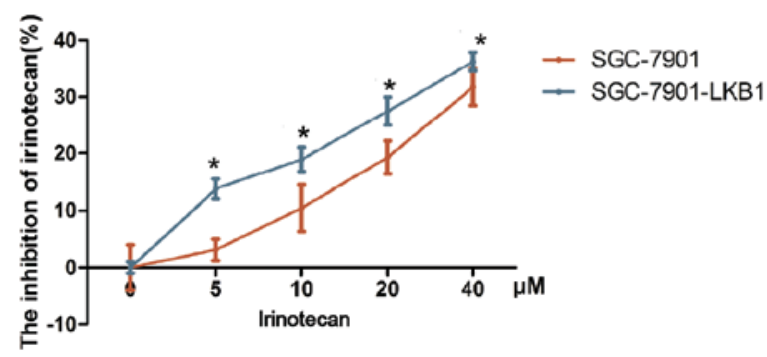

Figure 6. Effects of the expression of LKB1 on gastric cancer cell sensitivity to treatment with different anticancer drugs. Cells were grown and treated with various concentrations of anticancer drugs for $48 \mathrm{~h}$ and then subjected to a cell viability MTT assay. (A) Cells were treated with 25,50 or $100 \mu \mathrm{M}$ oxaliplatin. (B) Cells were treated with 10, 20, 40 or $80 \mu \mathrm{M} 5$-FU. (C) Cells were treated with 5, 10, 20 or $40 \mu \mathrm{M}$ irinotecan. Data are presented as the mean \pm standard error of the mean. ${ }^{\mathrm{P}}<0.05$, vs. the SGC-7901 cells. LKB1, liver kinase B1; 5-FU, fluorouracil.

with tumor-node-metastasis classification, gender or other clinicopathological factors (Table I).

Establishment of stable LKB1-expressing gastric cancer cells. The present study established the stable LKB1 protein-expressing SGC-7901 gastric cancer cell line using a lentivirus carrying $L K B 1$ cDNA. Data from the subsequent RT-qPCR and western blot analyses revealed that the SGC-7901-LKB1 cells exhibited higher levels of LKB1 mRNA and LKB1 protein, compared with the SGC-7901-wild-type cells $(\mathrm{P}<0.01$; Fig. 2).

Effect of the expression of LKB1 on the regulation of gastric cancer cell phenotypes. Restoration of the expression of LKB1 reduced tumor cell viability and migration rate, and induced cell cycle arrest at the G2 phase of the cell cycle (Figs. 3 and 4). It is known that LKB1 is an important regulatory factor in determining cell polarity (26), and that CD44 protein is an important cell adhesion molecule, which is expressed on the cell surface (27). To understand the effect of LKB1 on the expression of CD44 in SGC-7901 cells, the present study examined the expression of CD44 in the SGC-7901 and SGC-7901-LKB1 cell lines. As shown in Fig. 5, the number of CD44-expressing cells was significantly lower in the SGC-7901-LKB1 cells, compared with the SGC-7901 cells $(\mathrm{P}<0.05)$, indicating that the inhibition of tumor cell migration and adhesion by LKB1 may occur via suppression of the expression of CD44.

LKB1 increases gastric cancer cell sensitivity to anticancer drug treatment. The present study also assessed the effects of the expression of LKB1 on the sensitivity of gastric cancer cells to the chemotherapeutic drugs oxaliplatin, fluorouracil 5-FU and irinotecan. The results demonstrated that the
SGC-7901-LKB1 gastric cancer cells stably expressing LKB1 were significantly more sensitive to treatment with these anticancer drugs, compared with the SGC-7901 cells $(\mathrm{P}<0.05$; Fig. 5). This suggested that the expression of LKB1 may be important in enhancing the sensitivity of gastric cancer cells to anticancer drugs.

\section{Discussion}

The present study examined the expression of LKB1 in 63 gastric cancer tissue specimens and found that, although the expression of LKB1 was reduced in gastric cancer tissues, there was no association between the reduction in the expression of LKB1 and the available clinicopathological data for the patients. The present study also assessed the effects of the expression of LKB1 in gastric cancer cells on the regulation of cell viability, cell cycle, migration, expression of CD44 and sensitivity to oxaliplatin, 5-FU and irinotecan chemotherapeutic drugs. The results revealed that the expression of LKB1 reduced tumor cell viability and migration rate, and induced the cell cycle arrest of the tumor cells at the G2 phase of the cell cycle. The expression of LKB1 also inhibited the expression of CD44 in gastric cancer cells, and the gastric cancer cells stably expressing LKB1 were more sensitive to treatment with the anticancer drugs, compared with the control cells.

LKB1 acts as a tumor suppressor in lung and breast cancer and is able to suppress tumor progression $(21,23)$. In the present study, the protein expression of LKB1 was lost in gastric cancer tissues, whereas expression of the protein was observed in the normal mucosae adjacent to the tumor. However, an earlier study failed to identify $L K B 1$ mutations in sporadic gastric cancer (22). Therefore, the mechanism underlying the reduction in the expression of LKB1 in gastric cancer remains to be elucidated. Although mutations in LKB1 may not be 
common in gastric cancer, a previous study demonstrated that LKB1 protein affected the development and progression of gastric cancer in patients with Peutz-Jeghers syndrome, a disease that is characterized by gastrointestinal polyps and cancer of different organs. In contrast with the previous study, which reported no association between $L K B 1$ mutation and cancer, the Peutz-Jeghers investigation revealed an association between an LKB1 mutation and the development of gastric cancer. Thus, further investigation is required to assess the mechanism underlying the reduction in the expression of LKB1 in gastric cancer. In addition, a previous study have demonstrated that $L K B 1$ mutations are the major cause of the loss of expression of LKB1 in various other human types of cancer, including lung adenocarcinoma, cervical, breast, intestinal, testicular, pancreatic and skin cancer (28).

The in vitro data of the present study demonstrated a novel finding, which, to the best of our knowledge, has not been previously reported. This was that restoration of the expression of LKB1 reduces tumor cell viability and migration rate, and induces cell cycle arrest at the G2 phase of the cell cycle in tumor cells. Supporting these results, a previous study demonstrated that, in breast cancer, LKB1 overexpression led to significant inhibition of tumor cell invasion, reduced tumor growth in the mammary fat pad and microvessel density, and suppressed tumor metastasis to the lung (21). This LKB1 overexpression was associated with the downregulation of matrix metalloproteinase -2 and 9, vascular endothelial growth factor and basic fibroblast growth factor (21). In lung cancer, the expression of LKB1 inhibits the invasion capacity of lung cancer cells by suppressing the expression levels of tissue factor and vascular endothelial growth factor (23). These data support the hypothesis that $L K B 1$ is a tumor suppressor gene in lung and breast cancer, and the results of the present study suggested that $L K B 1$ is also a tumor suppressor gene in gastric cancer. Further investigation is required to confirm these results.

The results of the present study also demonstrated that the expression of LKB1 sensitized the gastric cancer cells to treatment with anticancer drugs. Further evaluation of this result may lead to the discovery of novel therapies for gastric cancer. In addition, the expression of LKB1 reduced the levels of CD44 in gastric cancer cells. CD44 is a cell-surface glycoprotein, which is involved in cell-cell interactions, cell adhesion and cell migration (29). The CD44 protein is involved in a variety of cellular functions, including lymphocyte activation, recirculation and homing, hematopoiesis and tumor metastasis (30). In human cancer, CD44 protein is a cell surface marker for breast and prostate cancer stem cells, is associated with the progression of head and neck cancer and is involved in the migration of ovarian cancer cells $(31,32)$.

The inhibition of gastric cancer cell migration by LKB1 may, therefore, occur through suppression of the expression of CD44 by LKB1. However, the preliminary results reported in the present study only partially explain the mechanism by which the reduced expression of LKB1 leads to the development of cancer, and further investigation is required to fully understand the role of LKB1 in the regulation of gastric cancer development and progression. In conclusion, the present study demonstrated that the LKB1 protein has tumor-suppressive activity in gastric cancer, and further investigation may lead to the development of novel therapies for the treatment of gastric cancer.

\section{Acknowledgements}

This study was supported, in part, by grants from the National Science Foundation of China (grant. nos. 81171952, 81272926, 31460304 and 81460374) and Jiangxi Provincial Department of Science and Technology, Technical Support Project (grant. no. 20133BBG70061, 2008). The authors would like to thank Dr Zhijun Luo of the School of Medicine, Boston University (Boston, MA, USA) and Dr Yong Xie of the Research Institute of Digestive Diseases, The First Affiliated Hospital of Nanchang University (Nanchang, China) for providing technical support.

\section{References}

1. Ferlay J, Shin HR, Bray F, Forman D, Mathers C and Parkin DM: Estimates of worldwide burden of cancer in 2008: GLOBOCAN 2008. Int J Cancer 127: 2893-2917, 2010.

2. He J, Gu D, Wu X, Reynolds K, Duan X, Yao C, Wang J, Chen CS, Chen J, Wildman RP, et al: Major causes of death among men and women in china. N Engl J Med 353: 1134-1134, 2005.

3. Fock KM: Review article: The epidemiology and prevention of gastric cancer. Aliment Pharmacol Ther 40: 250-260, 2014.

4. Øverby A, Zhao CM and Chen D: Plant phytochemicals: Potential anticancer agents against gastric cancer. Curr Opin Pharmacol 19: 6-10, 2014.

5. Scartozzi M, Galizia E, Verdecchia L, Berardi R, Antognoli S, Chiorrini S and Cascinu S: Chemotherapy for advanced gastric cancer: Across the years for a standard of care. Expert Opin Pharmacother 8: 797-808, 2007.

6. Lordick F, Allum W, Carneiro F, Mitry E, Tabernero J, Tan P, Van Cutsem E, van de Velde C and Cervantes A: Unmet needs and challenges in gastric cancer: The way forward. Cancer Treat Rev 40: 692-700, 2014.

7. Kubota E, Williamson CT, Ye R, Elegbede A, Peterson L, Lees-Miller SP and Bebb DG: Low ATM protein expression and depletion of p53 correlates with olaparib sensitivity in gastric cancer cell lines. Cell Cycle 13: 2129-2137, 2014.

8. Zhang S, Schafer-Hales K, Khuri FR, Zhou W, Vertino PM and Marcus AI: The tumor suppressor LKB1 regulates lung cancer cell polarity by mediating cdc 42 recruitment and activity. Cancer Res 68: 740-748, 2008

9. MacIver NJ, Blagih J, Saucillo DC, Tonelli L, Griss T, Rathmell JC and Jones RG: The liver kinase B1 is a central regulator of $\mathrm{T}$ cell development, activation and metabolism. J Immunol 187: 4187-4198, 2011.

10. Nakano A and Takashima S: LKB1 and AMP-activated protein kinase: Regulators of cell polarity. Genes Cells 17: 737-747, 2012.

11. Hezel AF and Bardeesy N: LKB1; linking cell structure and tumor suppression. Oncogene 27: 6908-6919, 2008.

12. Sebbagh M, Olschwang S, Santoni MJ and Borg JP: The LKB1 complex-AMPK pathway: The tree that hides the forest. Fam Cancer 10: 415-424, 2011.

13. Kyriakis JM: At the crossroads: AMP-activated kinase and the LKB1 tumor suppressor link cell proliferation to metabolic regulation. J Biology 2: 26, 2003.

14. Shaw RJ: LKB1 and AMP-activated protein kinase control of mTOR signalling and growth. Acta Physiol (Oxf) 196: 65-80, 2009.

15. Shaw RJ, Bardeesy N, Manning BD, Lopez L, Kosmatka M, DePinho RA and Cantley LC: The LKB1 tumor suppressor negatively regulates mTOR signaling. Cancer Cell 6: 91-99, 2004.

16. Li T, Leong MH, Harms B, Kennedy G and Chen L: MicroRNA-21 as a potential colon and rectal cancer biomarker. World $\mathrm{J}$ Gastroenterol 19: 5615-5621, 2013.

17. Miller RA, Chu Q, Le Lay J, Scherer PE, Ahima RS, Kaestner KH, Foretz M, Viollet B and Birnbaum MJ: Adiponectin suppresses gluconeogenic gene expression in mouse hepatocytes independent of LKB1-AMPK signaling. J Clin Invest 121: 2518-2528, 2011.

18. Luo Z, Zang M and Guo W: AMPK as a metabolic tumor suppressor: Control of metabolism and cell growth. Future Oncol 6: 457-470, 2010. 
19. Hemminki A, Markie D, Tomlinson I, Avizienyte E, Roth S, Loukola A, Bignell G, Warren W, Aminoff M, Höglund P, et al: A serine/threonine kinase gene defective in Peutz-Jeghers syndrome. Nature 391: 184-187, 1998.

20. Zhuang ZG, Di GH, Shen ZZ, Ding J and Shao ZM: Enhanced expression of LKB1 in breast cancer cells attenuates angiogenesis, invasion and metastatic potential. Mol Cancer Res 4: 843-849, 2006.

21. Liang X, Li ZL, Jiang LL, Guo QQ, Liu MJ and Nan KJ: Suppression of lung cancer cell invasion by LKB1 is due to the downregulation of tissue factor and vascular endothelial growth factor, partly dependent on SP1. Int J Oncol 44: 1989-1997, 2014.

22. Park WS, Moon YW, Yang YM, Kim YS, Kim YD, Fuller BG, Vortmeyer AO, Fogt F, Lubensky IA and Zhuang Z: Mutations of the STK11 gene in sporadic gastric carcinoma. Int J Oncol 13: 601-604, 1998 .

23. Livak KJ and Schmittgen TD: Analysis of relative gene expression data using real-time quantitative PCR and the 2(T) (-Delta Delta C) method. Methods 25: 402-408, 2001.

24. Luo LY, Huang W, Tao R, Hu N, Xiao ZX and Luo Z: ATM and LKB1 dependent activation of AMPK sensitizes cancer cells to etoposide-induced apoptosis. Cancer Lett 328: 114-119, 2013.

25. Bradford MM: A rapid and sensitive method for the quantitation of microgram quantities of protein utilizing the principle of protein-dye binding. Anal Biochem 72: 248-254, 1976.

26. Granot Z, Swisa A, Magenheim J, Stolovich-Rain M, Fujimoto W, Manduchi E, Miki T, Lennerz JK, Stoeckert CJ Jr and Meyuhas O, et al: LKB1 regulates pancreatic beta cell size, polarity and function. Cell Metab 10: 296-308, 2009.
27. Hopkins AM: A novel mechanism of regulating breast cancer. Breast Cancer Res 16, 2014.

28. Sanchez-Cespedes M, Parrella P, Esteller M, Nomoto S, Trink B, Engles JM, Westra WH, Herman JG and Sidransky D: Inactivation of LKB1/STK11 is a common event in adenocarcinomas of the lung. Cancer Res 62: 3659-3662, 2002.

29. Bourguignon LY, Singleton PA, Zhu H and Diedrich F: Hyaluronan-mediated CD44 interaction with RhoGEF and Rho kinase promotes Grb2-associated binder-1 phosphorylation and phosphatidylinositol 3-kinase signaling leading to cytokine (macrophage-colony stimulating factor) production and breast tumor progression. J Biol Chem 278: 29420-29434, 2003.

30. Babina IS, McSherry EA, Donatello S, Hill AD and Hopkins AM: A novel mechanism of regulating breast cancer cell migration via palmitoylation-dependent alterations in the lipid raft affiliation of CD44. Breast Cancer Res 16: R19, 2014.

31. Bourguignon LY, Zhu H, Shao L and Chen YW: CD44 interaction with c-Src kinase promotes cortactin-mediated cytoskeleton function and hyaluronic acid-dependent ovarian tumor cell migration. J Biol Chem 276: 7327-7336, 2001.

32. Wang SJ, Wong G, de Heer AM, Xia WL and Bourguignon LYW: CD44 variant isoforms in head and neck squamous cell carcinoma progression. Laryngoscope 119: 1518-1530, 2009. 